\title{
Predisposing factors of phlebitis in children treated with vancomycin
}

\author{
Niloofar Bahrami ${ }^{1}$, Maryam Tork-Torabi ${ }^{2}$, Sedigheh Talakoub $^{3}$, Mahboobeh Namnabati ${ }^{4}$ \\ 1. MSc of Pediatric Nursing, Nursing and Midwifery Care Research Center, Faculty of Nursing and Midwifery, Isfahan \\ University of Medical Sciences, Isfahan, Iran, Orcid ID: 0000-0002-4328-5523 \\ 2. MSc of Pediatric Nursing, Nursing and Midwifery Care Research Center, Faculty of Nursing and Midwifery, Isfahan \\ University of Medical Sciences, Isfahan, Iran, Orcid ID: 0000-0001-8420-7970 \\ 3. Master degree of Pediatric/ Department of Pediatric and Neonatal Nursing, School of Nursing and Midwifery, Isfahan \\ University of Medical Sciences, Isfahan, Iran, Orcid ID:0000-0001-6912-4907 \\ 4. Associate Professor of Pediatric Nursing/ Nursing and Midwifery Care Research Center, Faculty of Nursing and \\ Midwifery, Isfahan University of Medical Sciences, Isfahan, Iran, (Correspondence author), Tel: 031-37927507, E-mail: \\ namnabat@nm.mui.ac.ir, Orcid ID: 0000-0001-9956-5519
}

\begin{abstract}
Background and Aim: Considering widespread use of vancomycin in childeren and the occurrence of phlebitis related peripheral intravenous catheters (PIVC); we decided to determine Predisposing factors of phlebitis in the childeren receiving vancomycin.

Methods and Materials: This cross-sectional descriptive-analytic study included 145 children older than 1 month who had been admitted to a medical education center in Isfahan and were under treatment with vancomycin. The sampling method was convenience and phlebitis measuring instruments were used 24, 48 and 72 hours, after the peripheral intravenous catheter insertion for every child. Chi-square test and multinomial logistic regression tests were used to analyze the data.

Results: Chi-Square test showed a significant relationship between phlebitis and catheter place, catheter size and washing catheter with $0.09 \% \mathrm{NaCl}(\mathrm{p}<0.05)$. Multinomial logistic regression indicated that age $(\mathrm{p}=0.009)$, male gender $(\mathrm{p}=0.009)$, catheter placement in upper extremity $(\mathrm{p}=0.005)$, catheter No.24 $(\mathrm{p}=0.04)$, washing catheter with $0.09 \% \mathrm{NaCl}(\mathrm{p}<0.001)$, vancomycin concentration of $<5 \mathrm{mg} / \mathrm{ml}(\mathrm{p}=0.004)$ and infusion of total peripheral nutrition $(\mathrm{p}=0.017)$ and cephalosporins $(\mathrm{p}=0.025)$ significantly influenced incidence of phlebitis.

Conclusion: nurses can prevent phlebitis by selecting appropriate catheter considering the ratio of catheter to vein size, washing catheter with $0.09 \% \mathrm{NaCl}$ and use of the upper extremities for catheter insertion. The concentration of vancomycin should also be $<5 \mathrm{mg} / \mathrm{ml}$ and the infusion rate should not exceed $5-10 \mathrm{mg} / \mathrm{min}$. These factors have considerable importance when childeren receive total peripheral nutrition and cephalosporins along with vancomycin.
\end{abstract}

Key words: Incidence, Phlebitis, Pediatric, Vancomycin, Peripheral intravenous catheter (PIVC).

Received: July 8, 2019

Accepted: Mar 10, 2020

How to cite the article: Niloofar Bahrami, Maryam Tork-Torabi, Sedigheh Talakoub, Mahboobeh Namnabati.Predisposing factors of phlebitis in children treated with vancomycin. SJKU 2021;26(2):64-78

Copyright () 2018 the Author (s). Published by Kurdistan University of Medical Sciences. This is an open access article distributed under the terms of the Creative Commons Attribution-Non Commercial License 4.0 (CCBYNC), where it is permissible to download, share, remix, transform, and buildup the work provided it is properly cited. The work cannot be used commercially without permission from the journal 


\section{عوامل مستعدكننده فلبيت در كود كان بيمار تحت درمان با ونكومايسين}

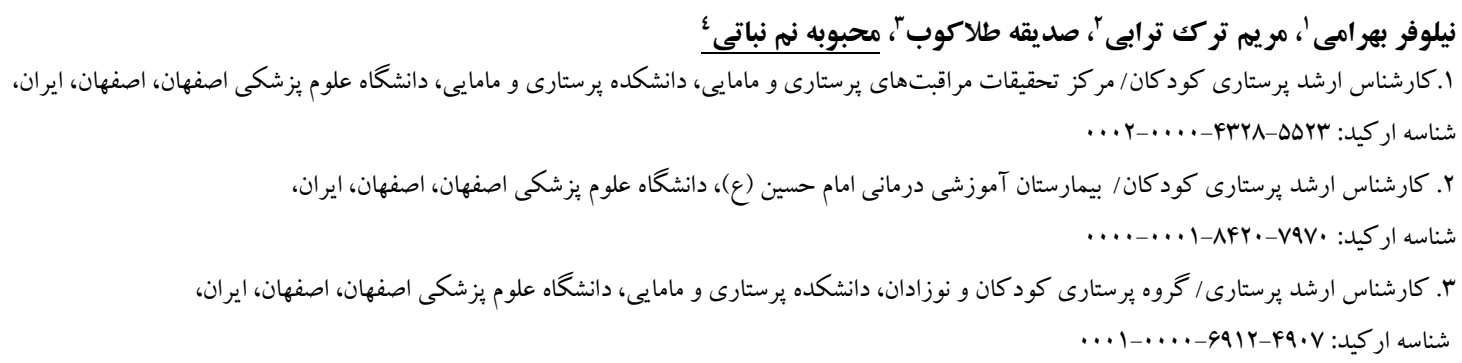

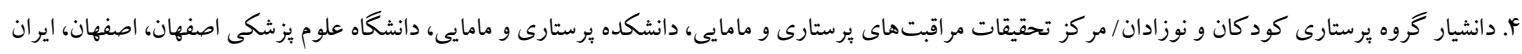

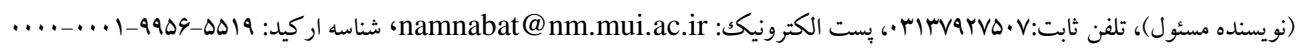

جكيuه

زمينه و هدف: با توجه به مصرف جشمخير ونكومايسين در كودكان و بروز فلبيت در كاتترهاى وريد محيطى؛ اين مطالعه با هدف تعيين عوامل مستعد كننده فلبيت در كود كان تحت درمان با ونكومايسين انجام شدر.

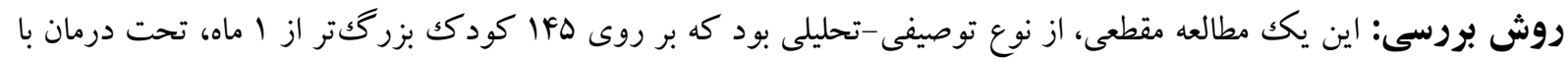

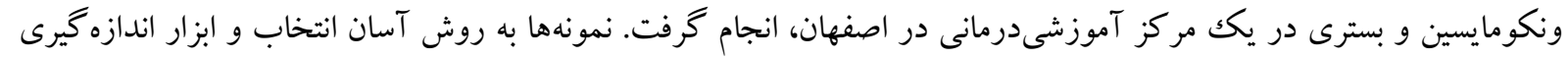

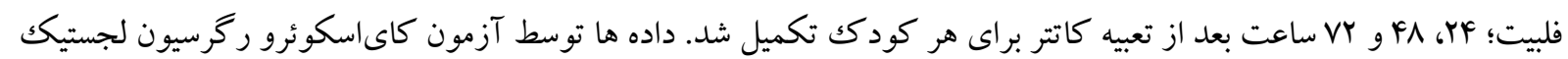
جند

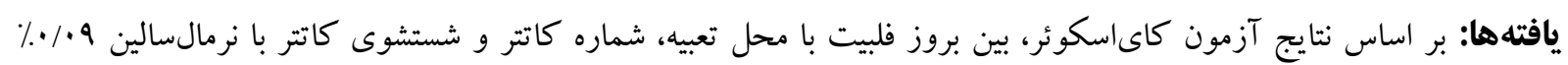

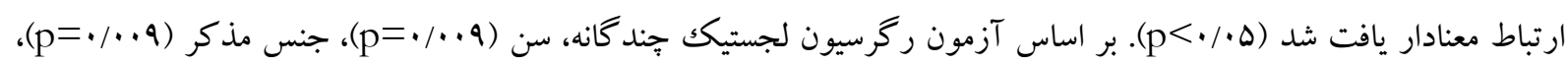

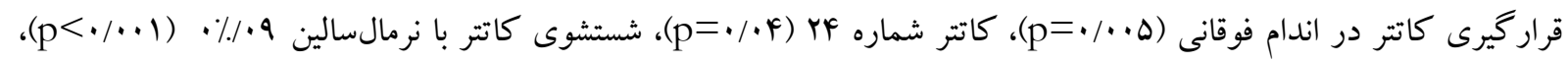

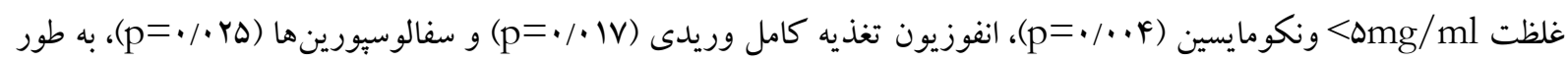
معنادارى بر روى احتمال بروز فلبيت تأثير گذار بودند.

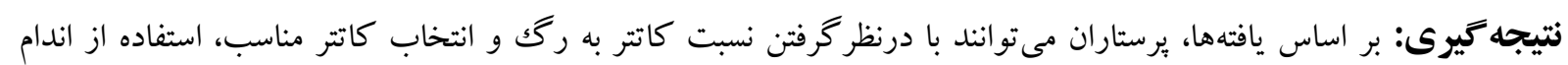

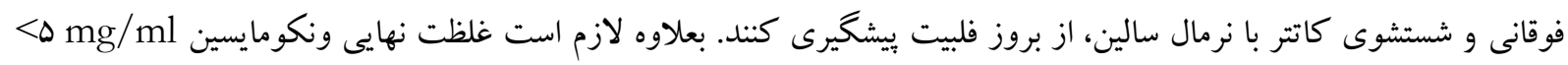

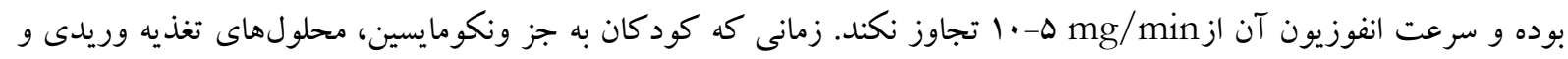
سفالوسيورين ها را نيز دريافت مى كند، اين موارد اهميت دوجندان مىيابد. وازههاى كليدى: بروز، فلبيت، كود كان، ونكومايسين، كاتتر وريد محيطى.

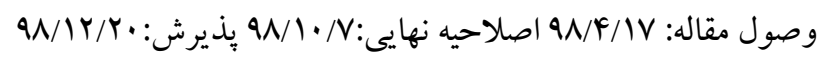


و انرزى آنها و ايجاد نارضايتى از خود را به دنبال دارد كه

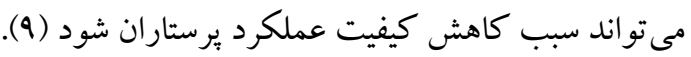
در راستاى شناسايى عوامل مرتبط با فلبيت، ييشخيرى از آن و افزايش طول عمر كاتترها، مطالعاتى در ايران انجام گرفنه

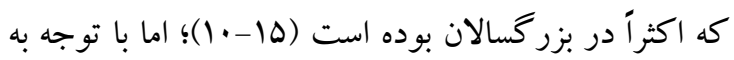
تفاوتهاى فيزيولوزيكى و روحى روانى كودكان نسبت به

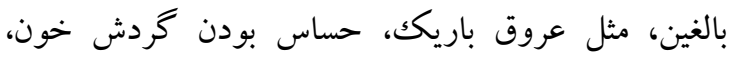
احتمال وجود كمَبى، نسبت بالاتر سطح بدن به وزن،

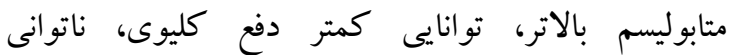
دركاتابوليسم دارو، خطر مسموميت دارويى، اضطراب كودكان و همكارى ضعيف آنها، كه خطر فلبيت و عوارض رگك گيرى مكرر را افزايش مىدهند (r و و14) و همجنين مصرف جشمخير ونكومايسين به عنوان استاندارد درمانى عفونتهاى كود كان كه خود به عنوان عامل تسريع كننده فلبيت شناخته شده است(Y)؛ اين مطالعه با هدف تعيين عوامل مستعد كننده فلبيت در كود كان تحت درمان با

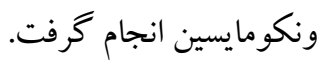

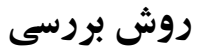

يثزوهش حاضر يكك مطالعه مقطعى از نوع توصيفى تحليلى و به روش مشاهدهاى است كه جامعه آمارى آن شامل كليه

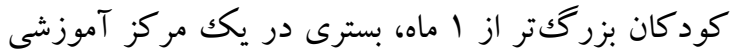
درمانى در اصفهان بودند كه در زمان اجراى يثزوهش

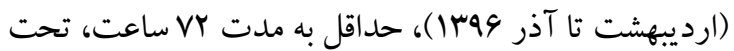
درمان با ونكومايسين با استفاده از كاتتر وريد محيطى قرار داشتند. معيارهاى خروج از مطالعه شامل اعلام عدم رضايت والدين به همكارى، ايجاد شرايط حاد و اورزانسى در

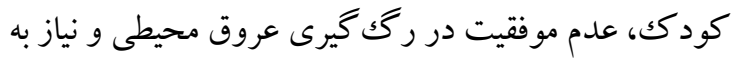
وصل كاتتر مركزى و ترخيص يا فوت كودك قبل مبل از اتمام

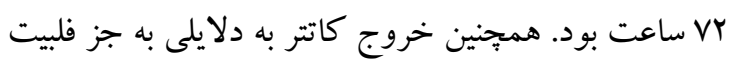

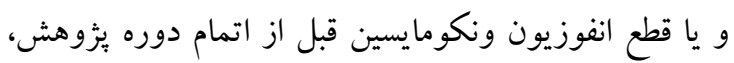

مقدمه

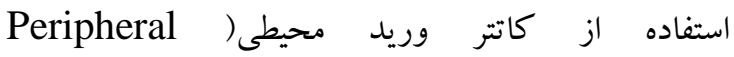
Intravenous Catheter: PIVC و تهاجمى جهت مايعدرمانى و انفوزيون داروها در كود كان بسترى است (1)، كه مانند هر روش درمانى ديخر، علاوه بر

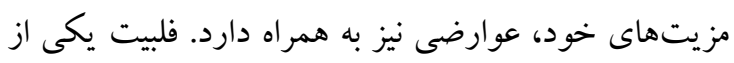
شايعترين عوارض قابل بيشخيرى كاتترهاى وريد محيطى و

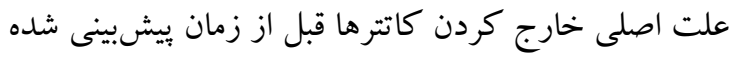

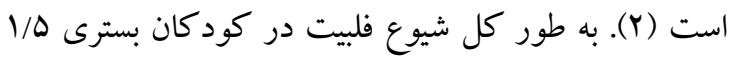

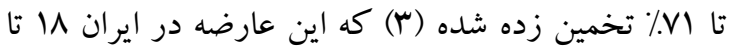

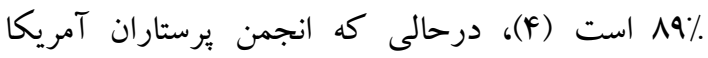
(American Nurses Association : ANA) شيوع قابل قبول فلبيت را ه درصد يا كمتر ذكر مى كند (ه).

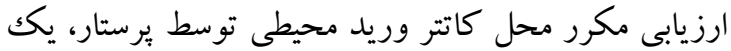

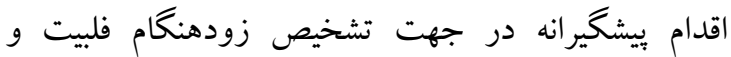
جلو گيرى از عوارض خطرناك قلبى ريوى آن شامل

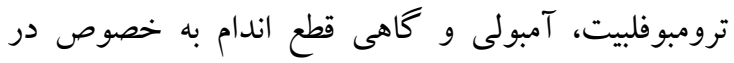

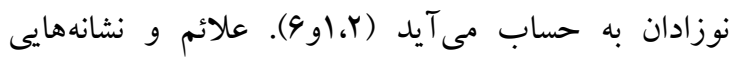
همجِون: درد، حساسيت، گرمى، تورم، قرمزى، طنابى شدن مسير وريد و كاهش سرعت جريان محلول علامتهاى بروزفلبيت بوده كه به دنبال آن لازم است كاتتر سريعاً

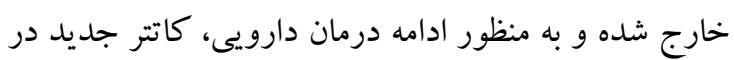

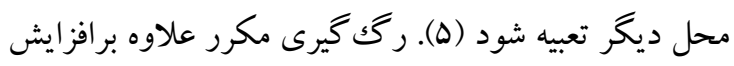
طول مدت بسترى، تحميل هزينههاى اقتصادى، افزايش احتمال ابتلا به عفونت، عدم آسايش، ايجاد درد و خحاطره نامطلوب براى كودك بيمار؛ سبب سخت تر شدن دستيابى إنى به عروق جديد و افزايش احتمال استفاده از روشهاى

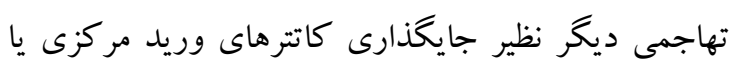

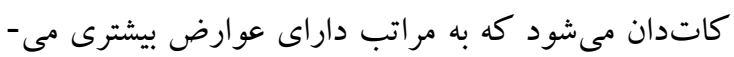

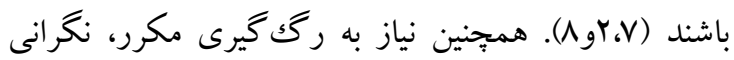

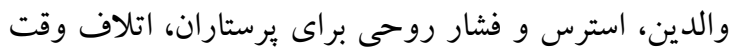


كارتى قرار مى گرفت كه مشخص كننده تحت بُزوهش بودن بيمار بود. يزوهشخر در شروع مطالعه توضيحات لازم

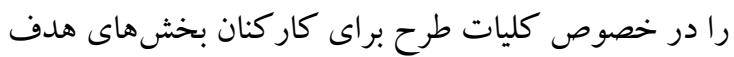
ارائه داد و همكارى آنها را جلب نمود. روش كار به اين صورت بود كه بعد از تعيين شركت كنندكان، توضيحات لازم در مورد هدف كار و شيوه اجرا به والدين كودكان ارائه شده و يس از جلب موافقت و كسب رضايتنامه كتبى از آنها، محل كاتتر وريد محيطى كودكى در زمان رگككيرى و FY TY، و و VY ساعت بعد از تعبيه كاتتر مشاهده و علائم فلبيت بررسى مىشد و در صورت مشاهده فلبيت در هر زمان از مطالعه، محل كاتتر سريعاً تعويض شده و مطالعه اين كودكك به اتمام مىرسيد. شر كت كنند كان اجازه داشتند كه در هر مرحله از يزوهش و در صورت عدم تمايل، از

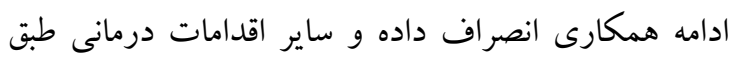

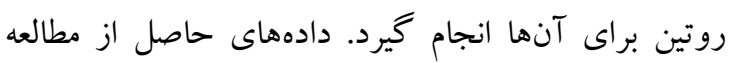

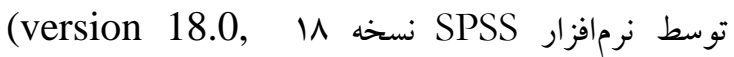
SPSS Inc., Chicago, IL, USA). آمارى توصيفى، كاىاسكوئر و ر رخرسيون لجستيك جند گانه، در سطح معنادارى هـ/ • ت تجزيه و تحليل شد.

\section{يافته ها}

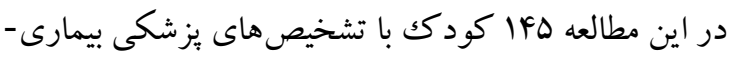

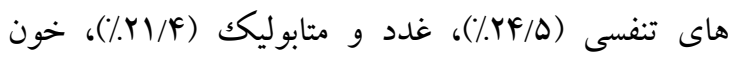

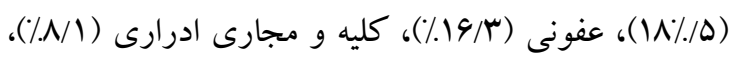

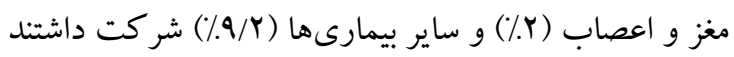

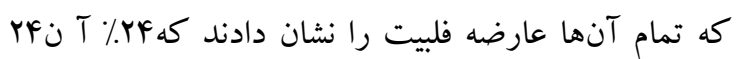

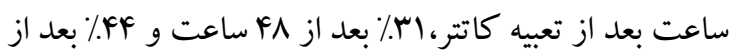
VI VI Vاعت ايجاد شد. ساير مشخصات در جدول ا آمده

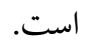

از معيارهاى خروج از مطالعه بود. حجم نمونه در سطح

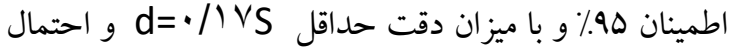

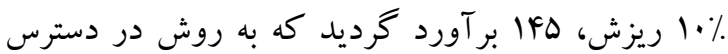

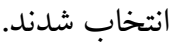
ابزار گردآورى دادهها شامل جّك ليست اطلاعات مربوط به متغيرهاى مورد بررسى و مقياس استاندارد فلبيت بود كه با توجه به اهداف و نمونهاى مورد بررسى انتخاب شد. مقياس استاندارد فلبيت بر اساس وجود علائم فلبيت شامل

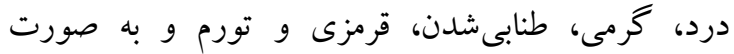
مشاهدهاى تكميل مى گردد. در اين مقياس به وجود علائم درد، گرمى و طنابى شدن محل كاتتر نمره ا و به عدم وجود آنها نمره صفر داده مى شود. در مورد علامت قرمزى به عدم وجود، نمره صفر؛ قرمزى خفيف، نمره ا و قرمزى

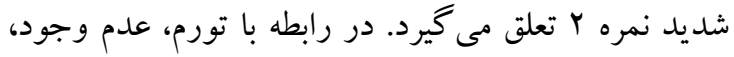

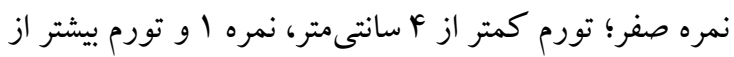

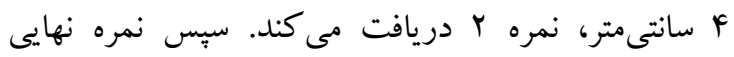
محاسبه و كسب حداقل ب نمره براى تشخيص فلبيت كافى

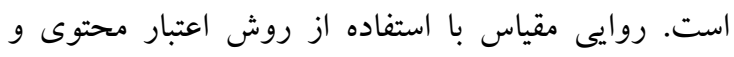

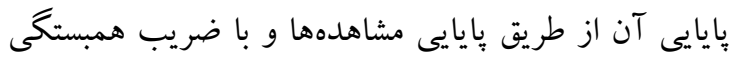
كرامر و فى براى مجموع نمرات در دو إن مشاهدهر بائر

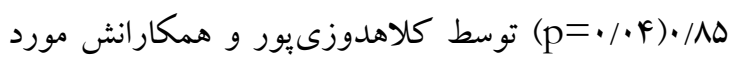

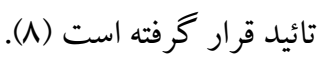
به منظور عدم سو گيرى و اجتناب از تورش، دو دانشجوى درى

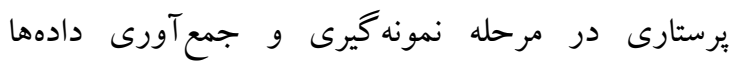

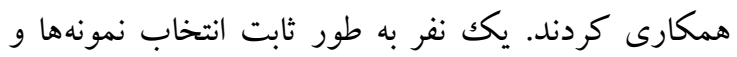

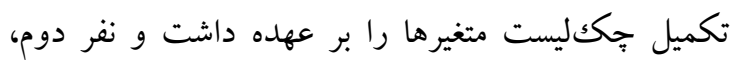
مسئول تكميل مقياس فلبيت بود. قبل از شروع كار، شرايط ورود به مطالعه، روش نمونه گيرى، كسب رضايت آكاهانه و شيوه گردآورى اطلاعات براى آنها توضيح داده شد.

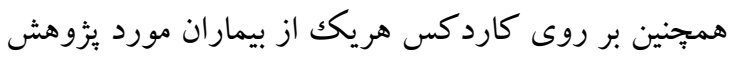


جدول ا: فراوانى متغير هاى مورد نظر در كودكان تحت درمان با ونكومايسين

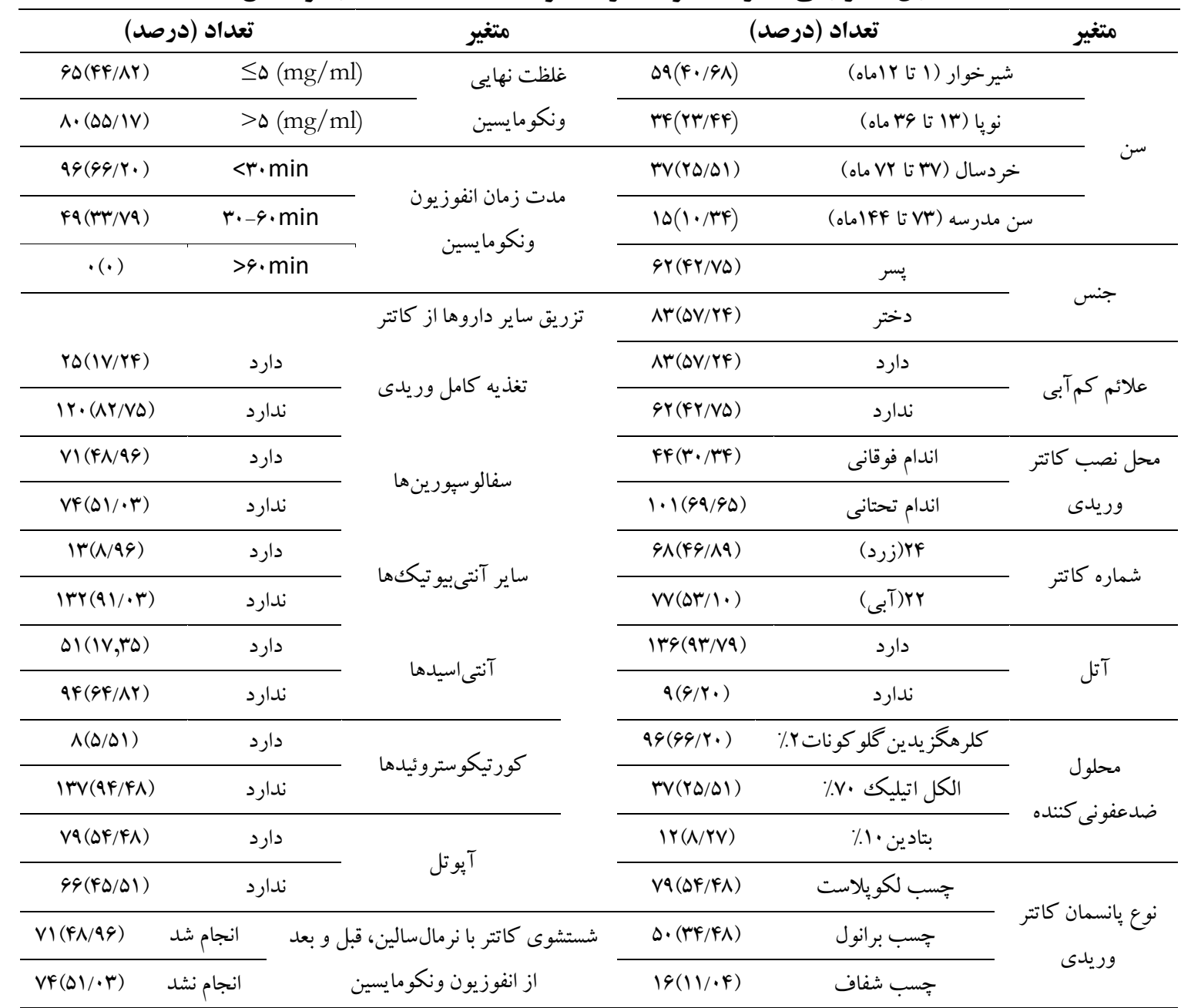

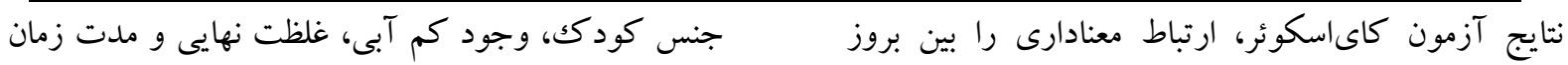
فلبيت و محل تعبيه و شماره كاتتر و شستشوى كاتتر با ب انفوزيون ونكومايسين، نوع محلول ضدعفونى كننده و نرمالسالين، قبل و بعد از انفوزيون ونكومايسين نشان داد انسمان در محل كاتتر، استفاده از آتل و انفوزيون ساير

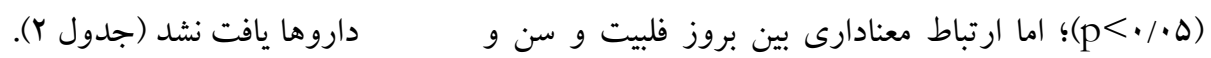
جدول r: ارتباط بين بروز عارضه فلبيت و متغيرها، در كود كان تحت درمان با ونكومايسين

\begin{tabular}{|c|c|c|c|c|c|c|}
\hline$p$ & $\chi^{2}$ & تعداد (درصد) & تعداد (درصد بعر & 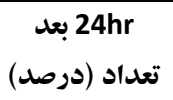 & متغير ها & \\
\hline \multirow{4}{*}{$\cdot / 9 K F$} & \multirow{4}{*}{ F/MIV } & $r G(F F / I)$ & $19(K Y / Y)$ & $I F(Y M / V)$ & شيرخوار & \multirow{4}{*}{ سن } \\
\hline & & $\Pi(\Gamma \wedge / Y)$ & $\Pi(\boldsymbol{Y} \Lambda / Y)$ & $\Lambda(Y \Psi / \Delta)$ & نويا & \\
\hline & & $r \cdot(\Delta F / I)$ & $1 \cdot(Y V / \cdot)$ & $V(\mid \wedge / 9)$ & خردسال & \\
\hline & & $\Delta(\Gamma / \mu)$ & $F(Y G / V)$ & $q(F \cdot / \cdot)$ & سن مدرسه & \\
\hline \multirow{2}{*}{$\cdot / 119$} & \multirow{2}{*}{$F / Y \Delta Q$} & $r Y(\Delta \mid / 9)$ & $r \cdot(M / T)$ & $1 \cdot(19 / 1)$ & يسر & \multirow{2}{*}{ جنس } \\
\hline & & $\mu r(r N / 9)$ & $r G(\Gamma, / \Gamma)$ & $r \Delta(r \cdot / l)$ & دختر & \\
\hline \multirow{2}{*}{$.19 \mathrm{TV}$} & \multirow{2}{*}{$\cdot / 9 F F$} & $\mu F(F \wedge / F)$ & $r V(r Y / \Delta)$ & $r Y(Y G / \Delta)$ & دارد & \multirow{2}{*}{ كم آبى } \\
\hline & & $r \cdot(f \mid / \cdot)$ & $19(r \cdot 19)$ & $\mid r(Y \mid / \cdot)$ & ندارد & \\
\hline$\cdot / \cdots$ & $r Y / 1 \cdot \Lambda$ & $V(10 / 9)$ & $1 \Lambda(4 \cdot / q)$ & $19(K F / Y)$ & اندام فوقانى & محل كاتتر \\
\hline
\end{tabular}


49

\begin{tabular}{|c|c|c|c|c|c|c|}
\hline & & $\Delta \varphi(\Delta 9 / \cdot)$ & $r \Lambda(Y \Lambda / \cdot)$ & $19(19 / \cdot)$ & اندام تحتانى & \\
\hline \multirow{2}{*}{$\cdot / \cdot \Delta$} & \multirow{2}{*}{$\Delta / 9 \Lambda$} & $r M(Y Y / \Lambda)$ & $Y I(Y Y / \Lambda)$ & $r Y(r / T)$ & (زرد) & \multirow{2}{*}{ شماره كاتتر } \\
\hline & & $r q(\Delta \cdot / 9)$ & $r \Delta(Y Y / \Delta)$ & $1 r(19 / 9)$ & r r (آبى) & \\
\hline \multirow{2}{*}{$\cdot / 49$} & \multirow{2}{*}{$r / 991$} & $G Y(F \Delta / 9)$ & $F r(r / 9)$ & MI(YY/A) & دارد & \multirow{2}{*}{ آتل } \\
\hline & & $Y(Y Y / Y)$ & $r(\Gamma / \mu)$ & $f(F f / f)$ & 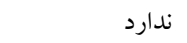 & \\
\hline \multirow{3}{*}{$\cdot / M$} & \multirow{3}{*}{$r / r q 1$} & $\kappa r(F F / \Lambda)$ & $r \Gamma(\Gamma / \Gamma)$ & $Y I(Y I / Q)$ & كلرهغزيدين & \multirow{3}{*}{ ضدعفونى كننده } \\
\hline & & $10(4 \cdot / \Delta)$ & $\operatorname{Ir}(r Y / F)$ & $1 \cdot(Y V / \cdot)$ & ال الكل & \\
\hline & & $9(\Delta \cdot / \cdot)$ & $r(19 / 99)$ & $f(\Gamma / \mu T)$ & بتادين & \\
\hline \multirow{3}{*}{.$/ 949$} & \multirow{3}{*}{ l/AIr } & $r q(F \Delta / 9)$ & $r \Delta(r \mid / 9)$ & $1 \Lambda(Y Y / A)$ & لكويلاست & \multirow{3}{*}{ بانسمان كاتتر } \\
\hline & & $11(F \cdot / v)$ & $9(r / / r)$ & $V(Y \Delta / Q)$ & جسب برانول & \\
\hline & & $\operatorname{IV}(F / / D \Lambda)$ & $\mid r(r \cdot / V 4)$ & $1 \cdot(Y \Delta / G Y)$ & קسب شفاف & \\
\hline \multirow{2}{*}{ • MYY } & \multirow{2}{*}{$r / r F$} & $\mu(\Delta \cdot / \Lambda)$ & $19(Y 9 / Y)$ & $1 r(Y \cdot / \cdot)$ & $\leq \Delta(\mathrm{mg} / \mathrm{ml})$ & \multirow{2}{*}{ ولظكو } \\
\hline & & $M(Y V / \Delta)$ & $r V(\Gamma / \Lambda)$ & $r Y(r \Lambda / \Lambda)$ & $>\Delta(\mathrm{mg} / \mathrm{ml})$ & \\
\hline \multirow{3}{*}{ •/AIr } & \multirow{3}{*}{$\cdot / 4 I V$} & $\operatorname{Rr}(K Y / \Lambda)$ & $\mu r(\Pi / \Gamma)$ & $Y Y(Y Y / Q)$ & $<r \cdot \min$ & \multirow{3}{*}{ مدان انفوزيون زمان } \\
\hline & & YY(FF/Q) & $\mid F(Y N / 9)$ & $1 r(Y q / \Delta)$ & $r \cdot-4 \cdot \min$ & \\
\hline & & & & & & \\
\hline \multirow{2}{*}{$\cdot \cdots$} & \multirow{2}{*}{$1 N / 9 \cdot \Delta$} & $\operatorname{rr}(9 \cdot 19)$ & $r \cdot(Y \Lambda / Y)$ & $\Lambda(11 / \Gamma)$ & دارد & \multirow{2}{*}{ سالين } \\
\hline & & $r \mid(Y \wedge / F)$ & $r q(r \Delta / 1)$ & $r V(r G / \Delta)$ & 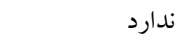 & \\
\hline \multicolumn{7}{|c|}{ تزريق ساير داروها از كاتتر } \\
\hline \multirow{2}{*}{$\cdot / \cdot \wedge \Delta$} & \multirow{2}{*}{ F/arr } & $V(Y N / \cdot)$ & $\Lambda(Y Y / \cdot)$ & $1 \cdot(f \cdot / \cdot)$ & دارد & \multirow{2}{*}{ تغذيه كامل } \\
\hline & & $\Delta V(F V / \Delta)$ & rN(rI/V) & $r \Delta(r \cdot / \Lambda)$ & 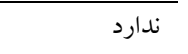 & \\
\hline \multirow{2}{*}{.1949} & \multirow{2}{*}{ •/AIr } & $\mu r(F 9 / 0)$ & $r \cdot(r \Delta / 1)$ & $M(Y \Delta / F)$ & دارد & \multirow{2}{*}{ سفالو سيورين ها } \\
\hline & & $M I(F \backslash / q)$ & $r G(Y \Lambda / Y)$ & $\operatorname{IV}(Y Y / \cdot)$ & ندارد & \\
\hline \multirow{2}{*}{$\cdot / T F A$} & \multirow{2}{*}{$r / 1.9$} & $V(\Delta r / \Lambda)$ & $\Delta\left(\Gamma_{N} / \Delta\right)$ & $1(\mathrm{~V} / \mathrm{V})$ & دارد & ساير آنتى بيوتيك \\
\hline & & $\Delta V(F r / r)$ & $F \mid(r) / 1)$ & $\mu F(Y \Delta / \Lambda)$ & ندارد & lo \\
\hline.$/ 9.1$ &.$/ 4 \cdot 9$ & $r r(F \Delta / 1)$ & $10(Y q / F)$ & $\mid r(Y \Delta / \Delta)$ & دارد & آنتت اسدها \\
\hline & & FI (Fr/G) & $\mu(\Pi / \cdot)$ & $r Y(Y M / F)$ & ندارد & الى اسيدما \\
\hline$\cdot \cdot \cdot \mathrm{vA}$ & $0 / .91$ & $f(\Delta \cdot / \cdot)$ & $\cdot()$ & $f(\Delta \cdot / \cdot)$ & دارد & كي تيك ست وئدها \\
\hline & & $9 \cdot(F+/ \Lambda)$ & $k q(T / / 9)$ & $M I(Y Y / 9)$ & ندارد & موزيانوسترويدما \\
\hline.$/ 9 Y 9$ &.$/ I F \wedge$ & $\mu F(F+/ \cdot)$ & $r \Delta(r / / 9)$ & $r \cdot(r \Delta / r)$ & دارد & آبو تال \\
\hline & & $r \cdot(F \Delta / \Delta)$ & $Y I(Y / / \Lambda)$ & $1 Q(Y Y / V)$ & ندارد & \\
\hline
\end{tabular}

كاى اسكوئر معنادارى مدل بررسى و مقدار احتمال كمتر از

به منظور بررسى عوامل مرتبط با احتمال بروز فلبيت و با

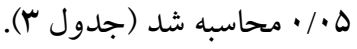

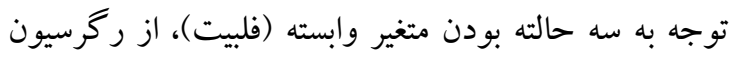

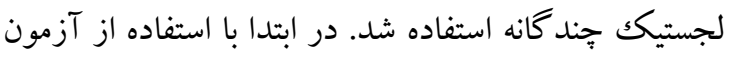

جدول ז: ارزيابى برازش مدل ركر إسيون لوجستيك

\begin{tabular}{|c|c|c|c|c|}
\hline \multicolumn{3}{|c|}{ آزمونهاى نسبت بخت } & \multirow{2}{*}{ معيار برازش مدل } & \multirow{2}{*}{ مدل } \\
\hline$p$ & $d f$ & ${ }^{\prime} \chi$ & & \\
\hline & & & $r \cdot 1 / 999$ & عرض از مبدأ \\
\hline$<\cdot / \cdot \cdot 1$ & $\Delta$. & $1 . F / 940$ & $19 V / T V Y$ & كل \\
\hline
\end{tabular}

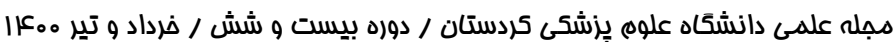


ساعت بعد است. در مجموع اين مدل 9N/1 درصد موارد متغير وابسته را به درستى بيشبينى مى كند (جدول F).
ميزان دقت بيشبينى مدل نيز در جدول F نشان داده شده است. طبق يافتها، كمترين دقت مربوط به بروز فلبيت،

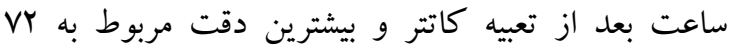

جدول ع: ميز ان دقت بيش بينى مدل

بيش بينى

\begin{tabular}{|c|c|c|c|c|}
\hline ميزان دقت & 72hr بعد از نصب كاتتر & 48hr بعد از نصب كاتتر & 24hr بعد از نصب كاتتر & مساهله سله \\
\hline$V \Psi \% / \Delta$ & f & $\Delta$ & ro & 24hr بعد از نصب كاتتر \\
\hline$\Delta F \% / / K$ & 10 & ro & 9 & 48hr بعد از نصب كاتتر \\
\hline $\mathrm{VV} / / \cdot$ & FV & 1. & f & 72hr بعد از نصب كاتتر \\
\hline $9 \Lambda \% / 1 \Lambda$ & $49 \% / 1 \Lambda$ & $r \Lambda \% / \mu$ & YF\% $/ / \Lambda$ & نسبت كلى \\
\hline
\end{tabular}

هر متغيرمستقل، ثابت در نظر گرفته شد. طبق نتايج جدول

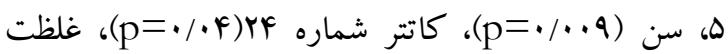
plomg/ml

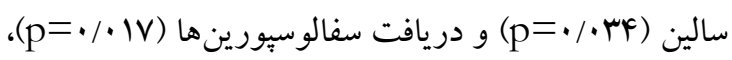
به طور معنادارى بر روى احتمال بروز فلبيت، FA ساعت بعد از تعبيه كاتتر نسبت به YF ساعت بعد تأثير كذار بودند.
براى بررسى تأثير هر متغير مستقل، سطح اول يعنى بروز

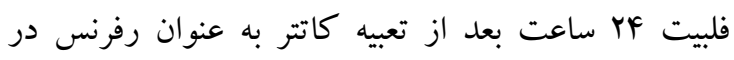

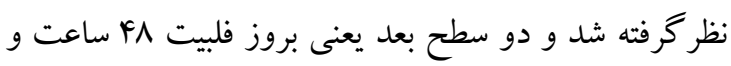

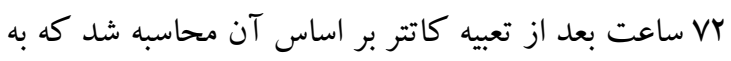
ترتيب در جدول ه و 9 نشان داده شده اند.آماره آزمون والد، معنى دارى متغيرها را نشان مىدهد. آخرين رسته در فر فر

جدول 0: بر آورد ضريب مدل ركرسيون لجستيك جند گانه براى نسبت بروز فلبيت، ^ع ساعت بعد از تعبيه كاتتر*

فاصله اطمينان 90\%

\begin{tabular}{|c|c|c|c|c|c|c|c|c|c|}
\hline & \multirow{2}{*}{ بر بخت ها بارد نسبت } & \multirow{2}{*}{$p$} & \multirow{2}{*}{$d f$} & \multirow{2}{*}{ والد } & \multirow{2}{*}{ استاندارد } & \multirow{2}{*}{ ير آورد } & \multirow{2}{*}{\multicolumn{2}{|c|}{ متغير ها }} \\
\hline حدبالا & حد يايين & & & & & & & & \\
\hline- & - & - & $\cdot / \cdots$ & 1 & $r V / \mu l l$ & $r / \Delta r I$ & $-r / / \Delta \cdot \Delta$ & ل از مبدأ & عرض \\
\hline$\Delta Q / V / \cdot V \Lambda$ & $r / 4 q V$ & $|K M / Y \mu|$ &.$/ 19$ & 1 & G/ArV & $1 / 199$ & $F / 994$ & شيرخوار & \\
\hline Y৯৭ठ/MMG & $r / T r \Delta$ & $V N / F \Delta F$ &.$/ \cdot 11$ & 1 & $\Delta / 9 / F$ & I/AFI & F/rar & نويا & \\
\hline 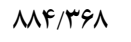 & I/OYY & r4/994 &.$/ \cdot r q$ & 1 & F/arr & l/GYF & $r / 9 \cdot r$ & خردسال & \\
\hline- & - & - & - & . & - & - & $0^{b}$ & سن مدرسه & \\
\hline $\mid F / V F q$ & . /AMA & $r / 019$ & $\cdot 1 \cdot 19$ & 1 & $r / 9 \Delta \Delta$ & . NMr & I/YOV & يسر & \\
\hline- & - & - & - & $\cdot$ & - & - & $0^{\mathrm{b}}$ & دختر & \\
\hline N/^91 &.$/ 494$ & $r / \cdot r$ & - MYAD & 1 & - /AQY & $\cdot / V D I$ & $\cdot / 2 \cdot 9$ & ندارد & $T<$ \\
\hline- & - & - & - & . & - & - & $0^{b}$ & دارد & \\
\hline r/ArA &.$/ 119$ & $\cdot / A \cdot V$ & $\cdot / \mathrm{WI}$ & 1 & $\cdot / \cdot A f$ & - NFF. & $-\cdot / Y 1 Q$ & اندام فوقانى & \\
\hline- & - & - & - & . & - & - & $0^{b}$ & اندام تحتانى & \\
\hline . /9ro & $\cdot / \cdot \Delta F$ & - TrSD &.$/ \cdot F$ & 1 & $F / Y \cdot q$ & . /VYV & $-1 / F 9 Y$ & (زرد) YF & \\
\hline- & - & - & - & . & - & - & $0^{b}$ & r r (Tبى) & \\
\hline rrV/GY. & $\cdot / T \Delta I$ & $V / \Delta \Delta V$ & . MFF & 1 & $1 / r \Delta \Delta$ & I/VMV & $r / \cdot r r$ & ندارد & آتل \\
\hline
\end{tabular}




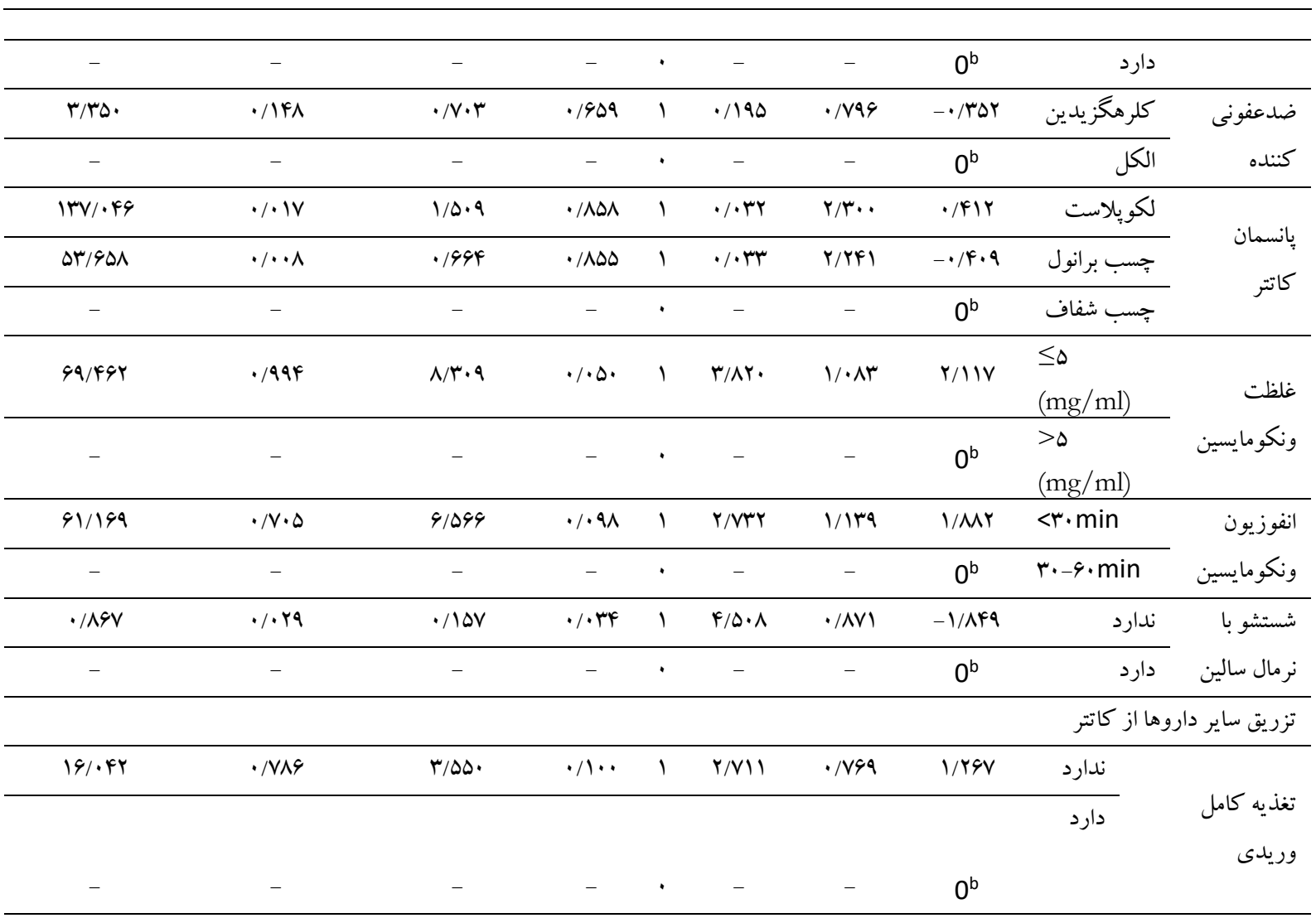

\begin{tabular}{|c|c|c|c|c|c|c|c|c|c|}
\hline $9 / 194$ & - & $|/ F F|$ & 194 & 1 & . MFY & - MFF & $\cdot / 494$ & ن ندارد & ساير آنتىبيوتيكك- \\
\hline- & - & - & - & . & - & - & $0^{b}$ & دارد & ها \\
\hline$\cdot / \Delta \cdot V$ & $\cdot / \cdots 1$ & $\cdot / \cdot Y I$ & $\cdot 1 \cdot 1 \mathrm{~V}$ & 1 & $9 / 90$ & l/94. & $-r / \Lambda V \Delta$ & 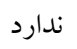 & \multirow{2}{*}{ سفالو سيورينها } \\
\hline- & - & - & - & . & - & - & $0^{b}$ & دارد & \\
\hline F/VIT & $\cdot$ MAT & $1 / 111$ & $\cdot / \mathrm{MV}$ & 1 & $\cdot / \cdot r$ & $\cdot / \mathrm{VTV}$ & $\cdot 11 \cdot 0$ & 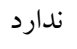 & \multirow{2}{*}{ آنتى اسيدها } \\
\hline- & - & - & - & . & - & - & $0^{b}$ & دارد & \\
\hline & rr|rIVI/99I & rr.rIVI/99I & - & 1 & - & $\cdot / \cdots$ & 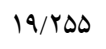 & 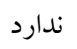 & \multirow{2}{*}{ كور تيكوستروئيدها } \\
\hline- & - & - & - & . & - & - & $0^{b}$ & دارد & \\
\hline Y/TVG &.$/ 1149$ & $\cdot / \Delta 9 Y$ & $\cdot / 419$ & 1 & $\cdot / 90 \mathrm{r}$ & $\cdot$ /VIF & $-\cdot / \Delta V 9$ & 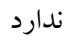 & \multirow{2}{*}{ آيو تل } \\
\hline- & - & - & - & - & - & - & $0^{b}$ & دارد & \\
\hline
\end{tabular}

*The reference category: $24 \mathrm{hr}$ after peripheral intravenous catheter (PIV) insertion

$\chi^{\top}$ : Chi-Square test

df: degree of freedom

$\mathrm{p}$ : $\mathrm{p}$ value

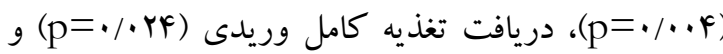

همجِين نتايج جدول 9 حاكى از تأثير معنادار سن

سفالوسبورينها (pD+/p) بر روى احتمال بروز فلبيت،

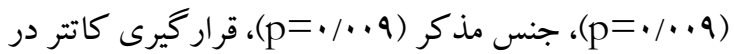

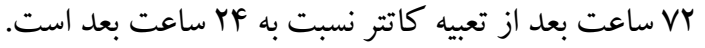

اندام فوقانى (ه)/p=•)، شستشوى كاتتر با نرمال سالين

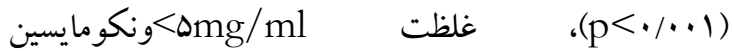

همله علمى دانشكاه علوم يِشكى كردستان / دوره بيست و شش / فراداد و تير م.ع|| 


\begin{tabular}{|c|c|c|c|c|c|c|c|c|c|}
\hline \multicolumn{2}{|c|}{ فاصله اطمينان 90٪ } & \multirow{2}{*}{ بر برت } & \multirow[b]{2}{*}{$p$} & \multirow[b]{2}{*}{$D f$} & \multirow{2}{*}{ مقدار } & \multirow[b]{2}{*}{ خطانداى } & \multirow[b]{2}{*}{ بِ بارآورد } & \multirow{2}{*}{\multicolumn{2}{|c|}{ متغير ها }} \\
\hline حدبالا & حديايين & & & & & & & & \\
\hline- & - & - & . & 1 & .191. & r/ATV & $-Y / 9 M \Lambda$ & ز مبدأ & عرض \\
\hline $1499 / 199$ & r/AVT & $q 4 / Q . r$ &.$/ 19$ & 1 & G/MY & $1 / 091$ & F/IVr & شيرخوار & \\
\hline$r 99 V / \cdot M I$ & r/YOY & W/arV & $.1 \cdot 19$ & 1 & $\Delta / \Lambda \cdot r$ & $1 / A \cdot A$ & $\varphi / r \Delta G$ & نويا & \\
\hline YIDQ/QFA & $1 / 491$ & $\Delta F / A Y I$ & س & 1 & F/OGK & I/AVF & $f / \ldots F$ & خردسال & سي \\
\hline- & - & - & - & . & - & - & $0^{\mathrm{b}}$ & سن مدرسه & \\
\hline$r Y / 9 Y V$ & I/GFV & $V / r 49$ &.$/ \cdots 9$ & 1 & G/AYA & ./VGF & $1 / 99 V$ & يسر & \\
\hline- & - & - & - & . & - & - & $0^{b}$ & دختر & جس جس \\
\hline$|r / \cdot F|$ & - /OFY & $r / 9 \Delta \Lambda$ & $\cdot /$ TYA & 1 & $1 / F \Delta 1$ & $\cdot / 111$ & $\cdot / 9 \vee \wedge$ & 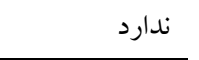 & \\
\hline- & - & - & - & . & - & - & $0^{b}$ & دارد & إبا \\
\hline.$/ 494$ &.$/ \cdot 14$ & $\cdot / \cdot \sqrt{ } 9$ & $\% / \cdots \Delta$ & 1 & $V / V \Delta \Lambda$ &.$/ 9 Y \Delta$ & $-Y / \Delta V G$ & اندام فوقانى & (كات \\
\hline- & - & - & - & . & - & - & $0^{b}$ & اندام تحتانى & لح بح \\
\hline $1 / M F \Lambda$ & .1 .94 & $\cdot /$ TqF & .1110 & 1 & Y/FAY & $\cdot / \mathrm{WV}$ & $-1 /$ YYF & (jرد & شها مكاتت \\
\hline- & - & - & - & . & - & - & $0^{b}$ & r Y (آبى) & سمارة قد \\
\hline rII/VG. & $\cdot / \mid \mathrm{VI}$ & $9 / .19$ & . & 1 &.$/ 9 \vee 9$ & I/AIV & $1 / v 9 \Delta$ & 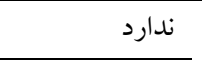 & TH \\
\hline- & - & - & - & . & - & - & $0^{b}$ & دارد & آل مل \\
\hline $9 / \cdot 10$ & .1 .91 & $\cdot / 9 \cdot 0$ & . /ArY & 1 & $\cdot / \cdots V$ & $1 / 1 V r$ &.$- / .99$ & كلرهخز يدين & 1. \\
\hline- & - & - & - & . & - & - & $0^{b}$ & الكل & صu \\
\hline 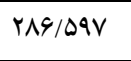 &.$/ \cdot 1 r$ & $1 / 9 \cdot r$ & $\cdot / A \cdot 1$ & 1 & .1 .94 & $r / \Delta \Delta Q$ & .1944 & لكويلاست & \\
\hline$|F| / V q q$ &.$/ 1$. & $1 / 19 V$ &.$/ 90$. & 1 & $\% \mu$ & $r / F F q$ &.$/ 10 \Delta$ & جِب برانول & بِانسمان كاتتر \\
\hline- & - & - & - & . & - & - & $0^{b}$ & جسب شفاف & \\
\hline TAF/GY. & $r / 911$ & $r q / 1 r q$ & 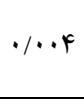 & 1 & $\Lambda / f \cdot \Delta$ & $1 / 194$ & $r / r V Y$ & $\begin{array}{l}\leq_{\Delta} \\
(\mathrm{mg} / \mathrm{ml})\end{array}$ & 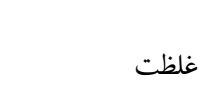 \\
\hline- & - & - & - & $\cdot$ & - & - & $0^{\mathrm{b}}$ & $\begin{array}{l}>\diamond \\
(\mathrm{mg} / \mathrm{ml})\end{array}$ & ونكومايسين \\
\hline$r Y / \cdot Y l$ & . MFF & $r / r Y_{1}$ &.$/ Y 99$ & 1 & $1 / \cdot W$ & $1 / 109$ & $1 / T_{\cdots}$ & $<r \cdot \min$ & انفوزيون \\
\hline- & - & - & - & . & - & - & $0^{b}$ & $r \cdot-9 \cdot \min$ & ونكومايسين \\
\hline.$/ 1 Y$ & . / r & $.1 \cdot 19$ & $\cdot \cdots$ & 1 & $19 / r \cdot r$ & $Y \cdot Y \wedge$ & $-F / I r V$ & 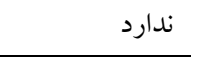 & شتشو با نرمال \\
\hline- & - & - & - & . & - & - & $0^{b}$ & دارد & سالين \\
\hline & & & & & & & & كاتتر & تزريق ساير داروها ا \\
\hline$\Delta r / l \Lambda r$ & I/TIV & $1 / 499$ &.$/ \cdot Y F$ & 1 & $\Delta / \cdot v \cdot$ &.$/ 9 F F$ & r/TYF & 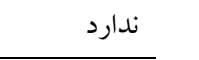 & لخ لخذ \\
\hline- & - & - & - & . & - & - & $0^{b}$ & دارد & \\
\hline$F / 0 \ldots$ &.$/ 194$ &.$/ 94 F$ & . /QTY & 1 & $\cdot / \cdots V$ & $\cdot / \Lambda \cdot r$ & -.1 .91 & 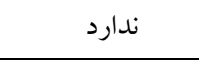 & ساير آنتىبيو تيككها \\
\hline
\end{tabular}




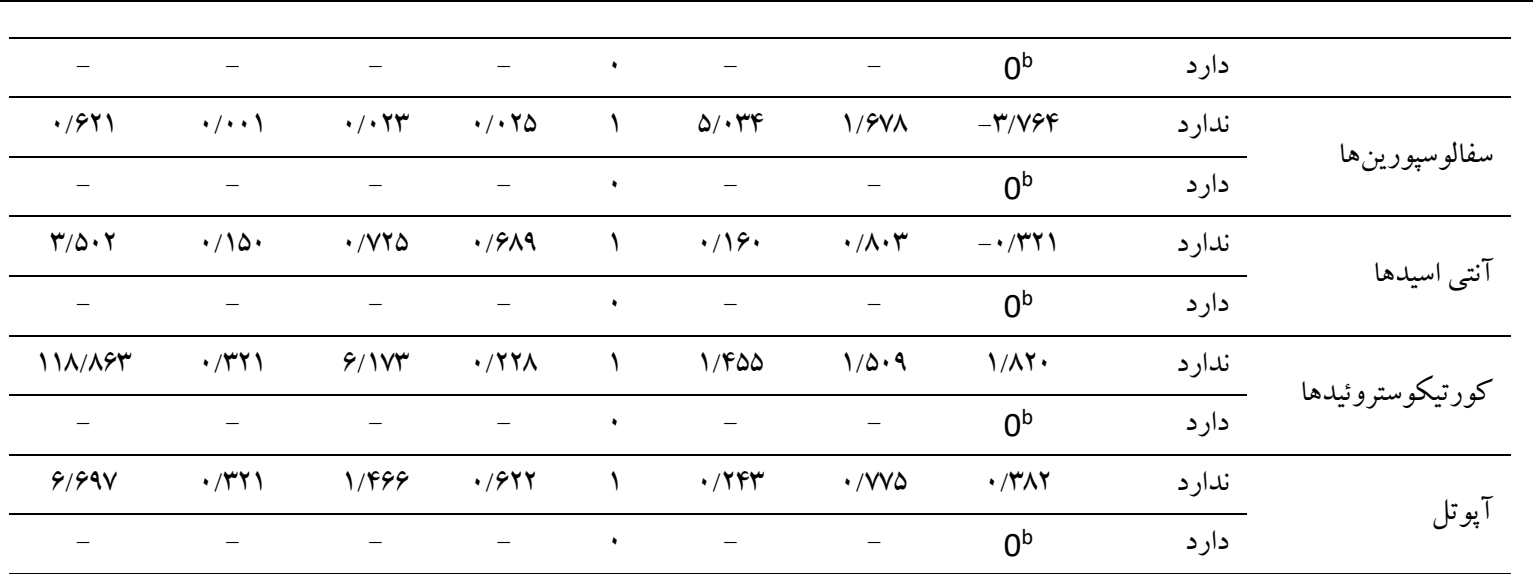

*The reference category: $24 \mathrm{hr}$ after peripheral intravenous catheter (PIV) insertion

$\chi^{\Upsilon}$ : Chi-Square test

df: degree of freedom

$\mathrm{p}$ : $\mathrm{p}$ value

اندام داراى كاتتر و كاهش سرعت جريان محلول براى

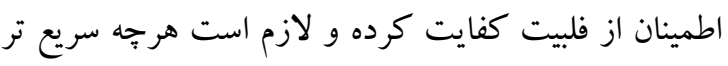
در ايران، ميانگين ساعت ماندكارى كاتتروريد محيطى

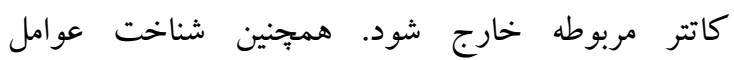

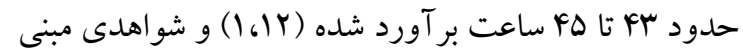
مستعدكننده فلبيت و ييشخيرى از آن براى افزايش كيفيت بر ماندكارى كاتتر بعد از VY يا و9 ساعت يافت نشد.

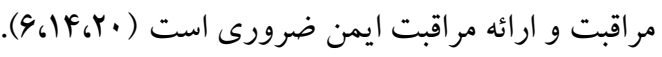
در اين مطالعه آزمون كاىاسكوئر رابطه معنادارى بين سن و و مرون

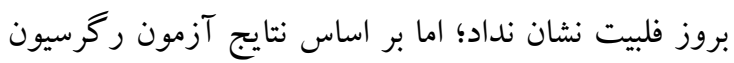

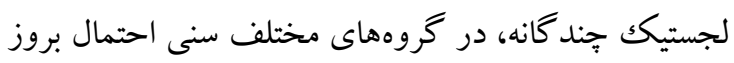
فلبيت YN ساعت و VY ساعت بعد از تعبيه كاتتر به طور معنادارى بيشتر از YF ساعت بعد است كه اين احتمال در

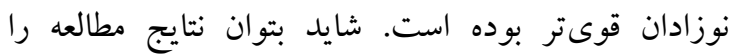
همراستا با برخى مطالعات دانست كه سن كمتر را از عوامل

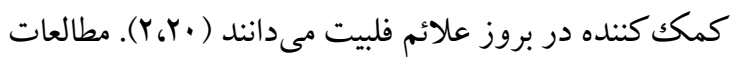

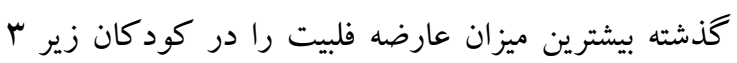
سال به خصوص شيرخواران زير يكسال بيان كرده اند (Y). از آنجا كه عواقب بروز فلبيت در اين شيرخواران خطرناك تر است؛ بنابراين حساسيت بيشتر يرستاران را نيز مى طلبد.

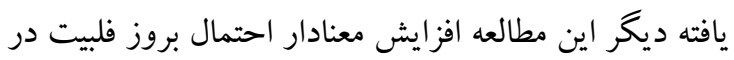
جنس مذكر، VY ساعت بعد از تعبيه كاتتر بوده است؛ اما از آنجاكه نتايج مطالعات بيشين در اين رابطه ضد و نقيض مطالعات مختلف نشان دادهاند كه هرجه از زمان تعبيه كاتتر بكذرد، احتمال بروز فلبيت بيشتر مىشود (IV). در مطالعه

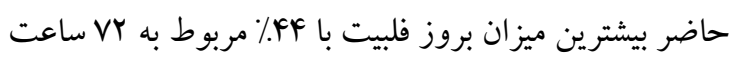

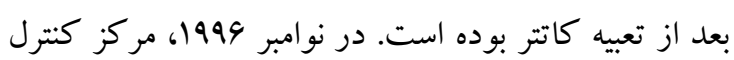

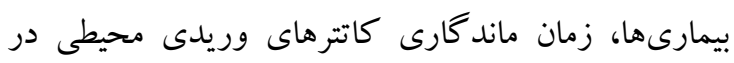

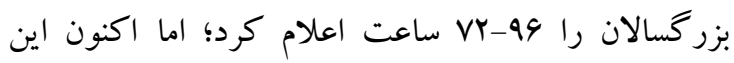
روتين تغيير كرده و تا زمانى كه كاتتر قابليت استفاده داشته

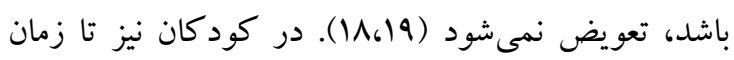

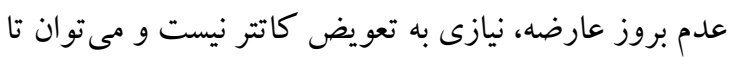
FF امرى ضرورى است؛ زيرا عدم تشخيص زودهنكام فلبيت

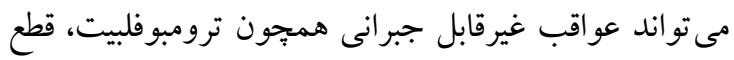

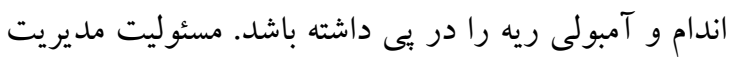
كاتتر بر عهده يرستاران است. يرستاران بايد هوشيار باشند

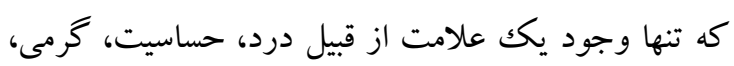
تورم، قرمزى، طنابى شدن مسير وريد، سرد بودن انتهاى 
مطالعه Urbanetto و همكارانش همخو انى دارد (Yr). احتمالاً عدم ثابت كردن مناسب كاتتر و يا طول وريد استفاده شده دليل اين نتيجه است؛ اما آنجه حائز اهميت است، ارجحيت استفاده از اندام فوقانى نسبت به اندام تحتانى در تعبيه كاتتر وريدى در كود كان است. زمانى كه ارتباط بين بروز فلبيت با شماره كاتتر بررسى شد،

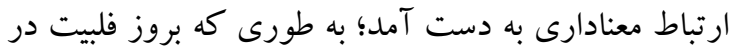

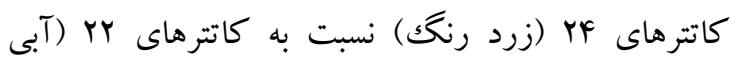

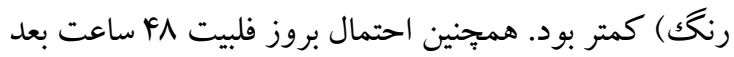
از تعبيه كاتتر در كاتتر زرد به طور معنادار كمتر گزارش شد هد كه مشابه با برخى مطالعات بيشين است (بr). البته برخى مطالعات يافته متفاوتى را گزارش كردهاند ( (IVGT). هرجند در رابطه با تأثير شماره كاتتر بر فلبيت اختلاف نظر وجود دارد؛ اما بر اساس قانون يو آزى (Poiseuille's Law)، نسبت بالاتر كاتتر /وريد و درنتيجه ايجاد گرفتكى در جريان عروق، عاملى به نفع ايجاد فلبيت است (YF)؛ به طوريكه

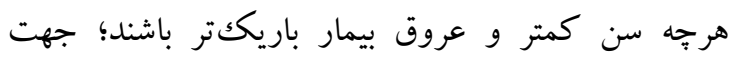

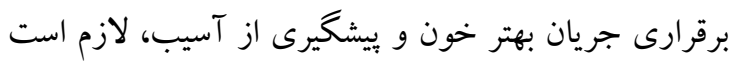

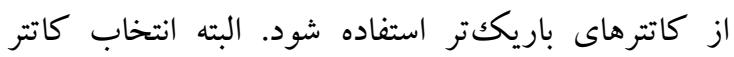

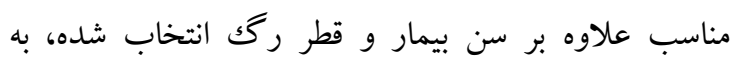
هدف دارودرمانى نيز بستخى دارد (Yه).

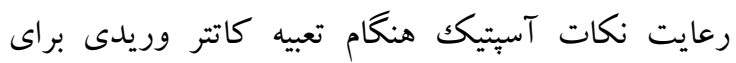
كاهش خطر عفونت و فلبيت لازم است (1))؛ اما هنوز در مورد محلول ضدعفونى كننده مؤثر اختلاف نظر وجود دارد. در اين مطالعه براى آمادهسازى يوست قبل از تعبيه كاتتر،

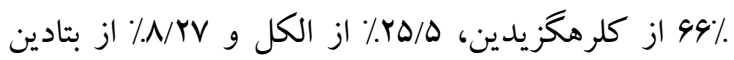
استفاده شده است. كلاهدوزىيور و همكاران، تفاوت

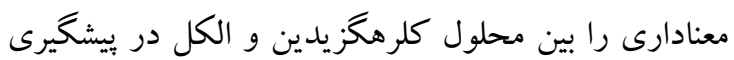
از فليت گزارش كردند (^)؛ اما در مطالعه حاضر، رابطه معنادارى بين نوع محلول ضدعفونى كننده و بروز فلبيت يافت نشد كه با برخى مطالعات بيشين همخوانى دارد

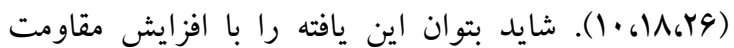

است (·F ·F)؛ بر اين اساس نمىتوان جنسيت را عامل افزايشى براى بروز فلبيت دانست. بر اساس نتايج مطالعه حاضر، ارتباط معنادارى بين وجود

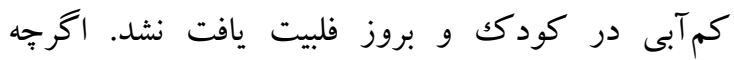

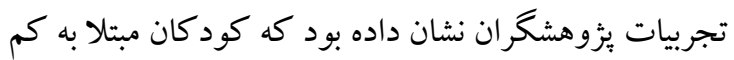
آبى، عارضه فلبيت را سريعتر نشان مىدهند. علاوه بر اين، مرورى بر متون نيز تأكيد مى كند كه كم آبى اختلال شايعى سئل در كودكان است كه منجر به كاهش حجم مايع داخل عروقى شده و عامل مستعد كننده بروز فلبيت به حساب مى آيد ( (Y) (9)؛ بنابر اين به نظر مىرسد انجام مطالعات بيشتر در اين زمينه و با حجم نمونه بالاتر ضرورى باشد.

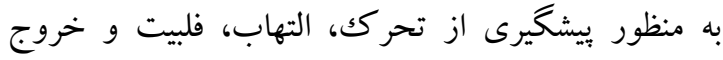
كاتتر، بِرستاران بايد وريدى را براى تعبيه كاتتر انتخاب

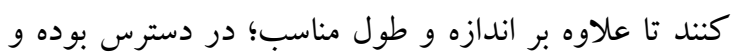

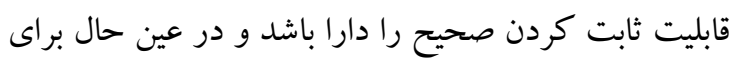

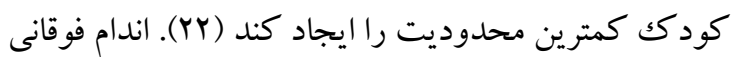
به خصوص يشت دست و ساعد، براى تعبيه كاتتر وريد

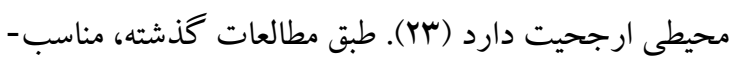

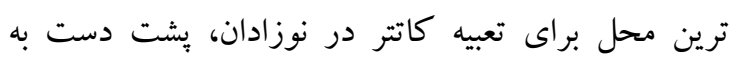

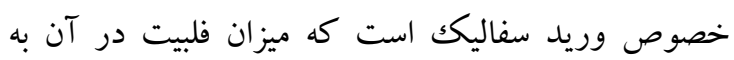
صورت معنادارى كمتر از ناحيه ساعد بوده است و در كود كان بزر كتر به دليل تحرك بيشتر، استفاده از وريدهاى

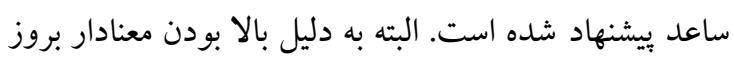

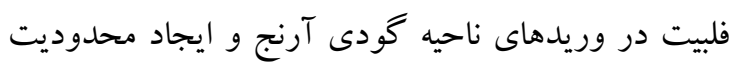
حركتى براى كودكى، استفاده از اين ناحيه براى تعبيه كاتتر

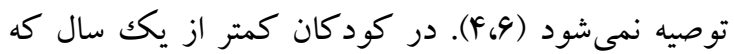

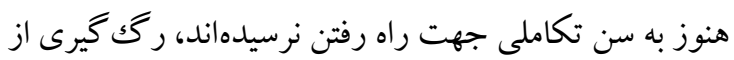

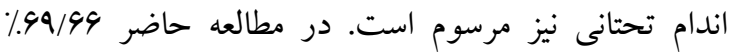
رگك گيرىها در اندام تحتانى بوده كه شايد بتوان دليل آن را درا با سن نمونها در ارتباط دانست. همجنين طبق نتايج آزمون ركرسيون، احتمال بروز فلبيت VY ساعت بعد از تعبيه كاتتر

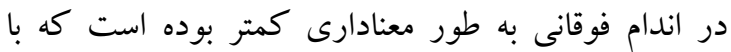


قرارگيرى كاتتر در محل داراى فلكسيون، از آتل استفاده شود (YN). نكته مهم در استفاده از آتل، رعايت يوزيشن

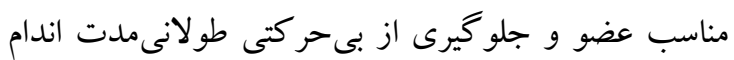
است (1). بر اين اساس ييشنهاد مىشود استفاده از آتل تنها

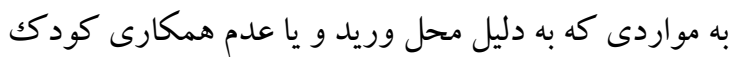

$$
\text { ضرورى است، محدود شود (Yr). }
$$

بر اساس مطالعات بيشين ميزان فلبيت در انفوزيون داروها، برابر مايع درمانى است (r، •r). در حال حاضر ونكومايسين

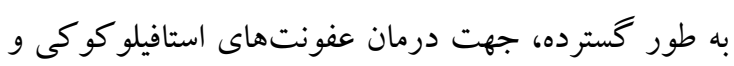

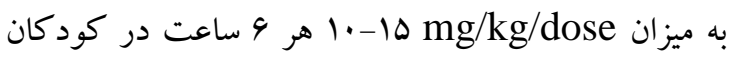
تجويز مىشود (Yq). طبق استانداردها، تزريق دارو يا

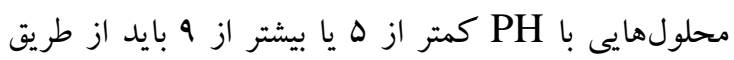

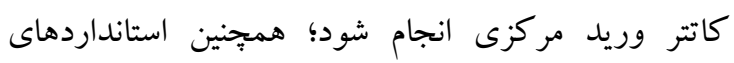
تزريقات داخل وريدى برستارى توصيه مى كند براى تزريق ونكومايسين با غلظت بيشتر از هيز از كاتتر وريد

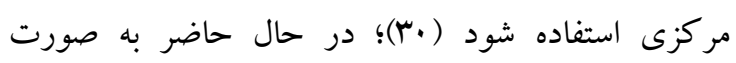

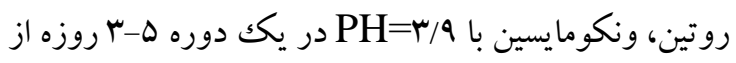

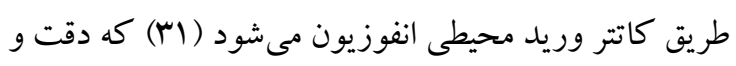

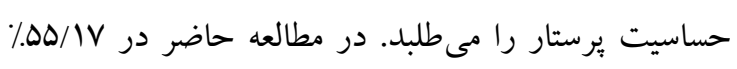

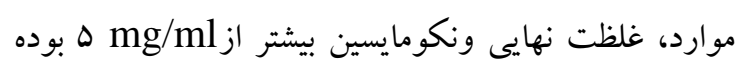
كه از طريق كاتتر وريد محيطى تزريق شده است. همجنين

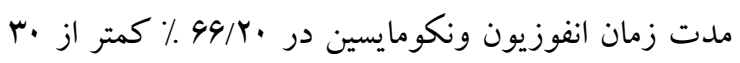

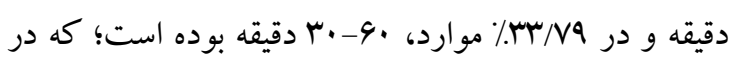

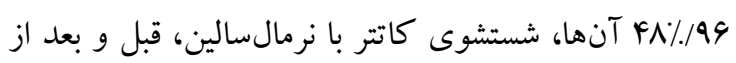

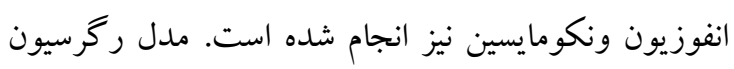

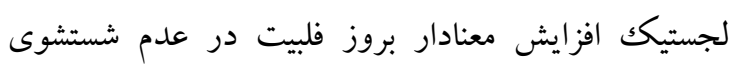

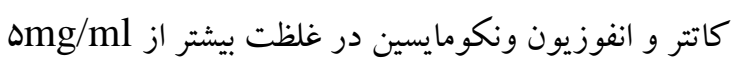

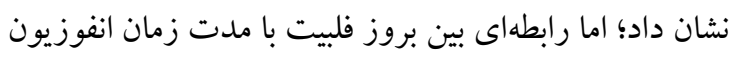

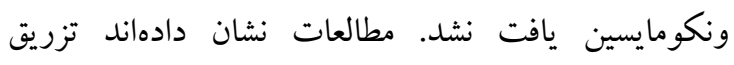
متناوب ونكومايسين با غلظت هmg/ml در مدت زمان زمان

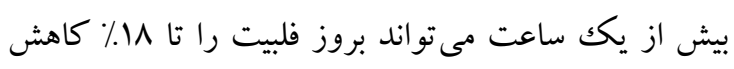
دهد (·r)؛ اما براساس تجربه، طولانى شدن زمان انفي انفوزيون برون
باكتريايى در نتيجه مصرف آنتىبيوتيكها و تغيير فلور طبيعى يوست و محيط بيمارستان در ارتباط دانست. هرجند ايمنى كلرهكزيدين در شيرخواران كمتر از ب ماه مورد بحث است؛ اما بر اساس دستورالعملهاى تعبيه كاتتر

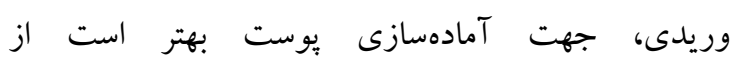

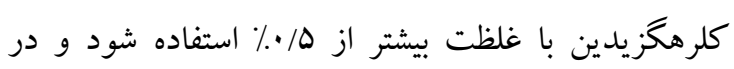

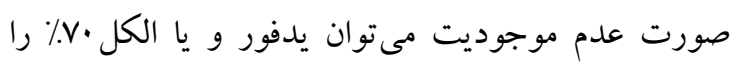

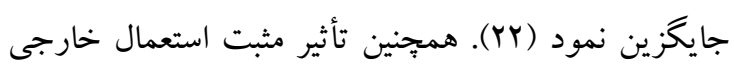

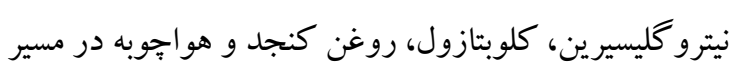

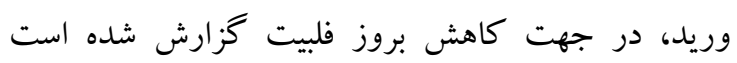

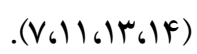
بانسمان محل كاتتر نقش مهمى در بيشخيرى از عفونت

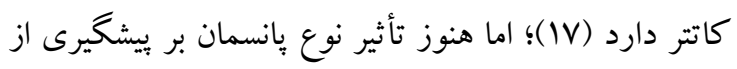
فلبيت مورد بحث است و مركز كنترل و وبيشخيرى از

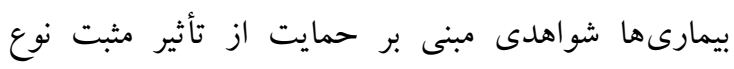

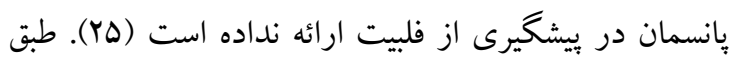

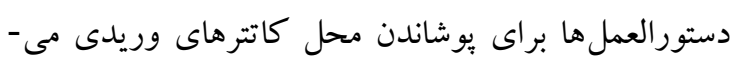

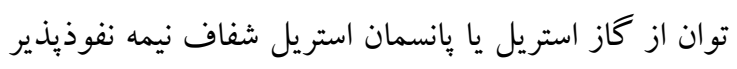

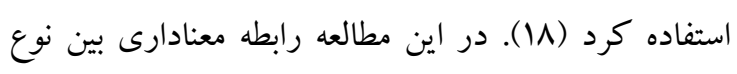

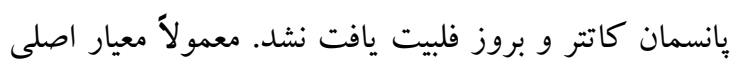

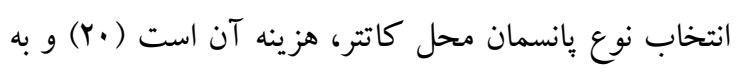
دليل گران بودن يانسمان شفاف، جايكزين كردن ساير باني

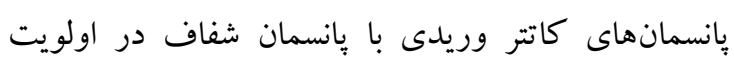

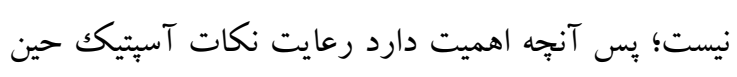

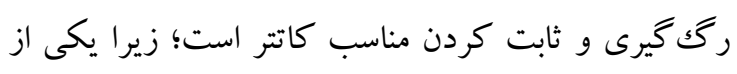
علل احتمالى بروز فلبيت عدم ثابت كردن صحيح كاتتر

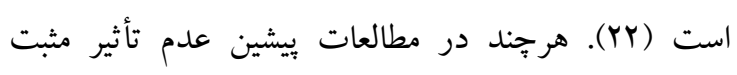

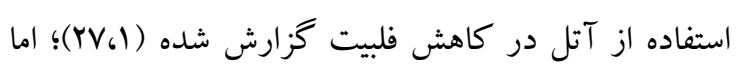
هماكنون در بخش كود كان، استفاده از آتل مرسوم است.

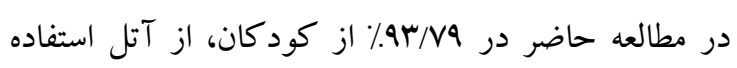

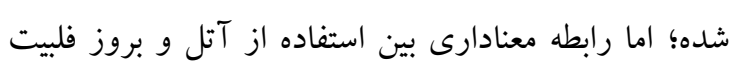
يافت نشد. Hugil توصيه مى كند تنها در نوزادان و يا زمان 


\section{نتيجه كيرى}

فلبيت شايع ترين عارضه قابل بيشخيرى كاتتر وريد محيطى است كه شيوع آن در كود كان ايرانى، با مقدار قابل قبول

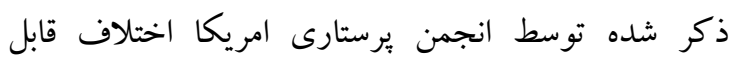

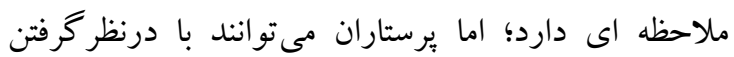
نسبت كاتتر به رگك و انتخاب كاتتر مناسب به همراه شستشوى كاتتر با نرمال سالين، قبل و بعد از تزريق ونكومايسين اين ميزان را كاهش دهند. همجنين لازم است

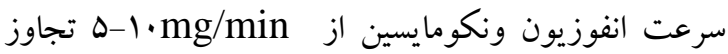
نكند. اين موارد به خصوص زمانى كه در كاردكس كودكك به جز ونكومايسين، محلولهاى تغذيه وريدى و سفالوسيورينها مشاهده مىشود، اهميت دوجندان مى يابد. همجِنين در زمان رگكى گيرى تاحدامكان استفاده از اندام فوقانى ارجحيت دارد. اميد كه رعايت اين نكات و ارزيابى مكرر كاتتر به خصوص در كودكان زير يكك سال بتواند از بروز فلبيت و عوارض آن ييشخيرى كند.

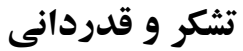

اين مطالعه با كد 11 19.9 توسط كميته اخلاق ويزوهش دانشگاه علوم يزشكى اصفهان تصويب شده است. بدينوسيله از معاونت يُزوهشى دانشكاه علوم يزشكى اصفهان،

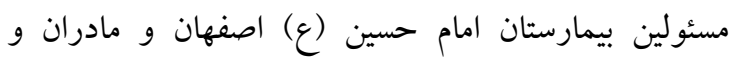
كودكانى كه در اجراى بُزوهش همكارى داشتهاند،

$$
\text { سباسگز ارى مىنماييم. }
$$

متناوب دركودكان، به خصوص كودكان يكسال به بالا سبب كاهش همكارى كودك و افزايش احتمال جابجايى

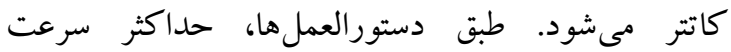

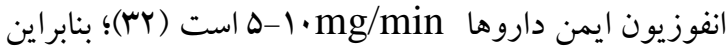
ييشنهاد مىشود به منظور ييشخيرى از فلبيت به جاى حساس بودن بر روى مدت زمان انفوزيون، به سرعت انفوزيون ونكومايسين دقت شود و شستشوى كاتتر قبل و بعد از تزريق ونكومايسين فراموش نشود. طبق مطالعات ييشين، هيارين لاكك هيج تأثيرى بر افزايش ماندكارى كاتتر ندارد؛

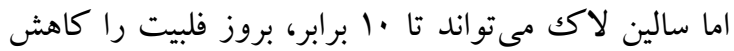
دهد (ها،بr). يافته ديخر مطالعه، ارتباط معنادار بين بروز فلبيت با تزريق سفالوسبورينها و تغذيه كامل وريدى (آمينواسيد و اينترالييد) از كاتتر مورد بررسى بود كه تأثير افزايشى اين آنتىبيوتيكها بر بروز فلبيت در مطالعات

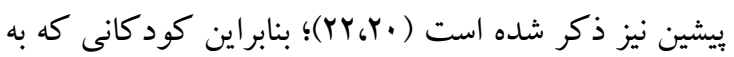
جز ونكومايسين اين دو دسته دارو را نيز دريافت مى كنند، نياز به كنترل بيشترى دارند. مطالعه حاضر محدوديتهايى نيز داشت كه شامل تعداد نمونه ها و عدم بررسى شدت فلبيت بود. همجنين به دليل

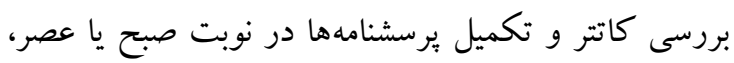

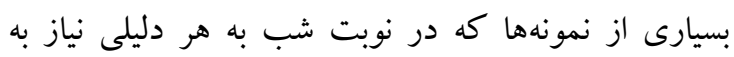

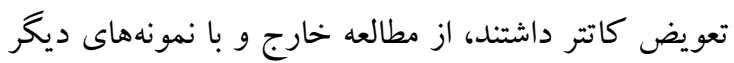

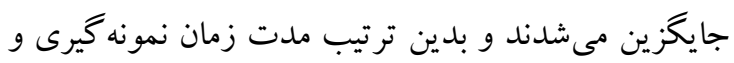
جمع آورى دادها طولانى شد.

\section{References}

1.Kalantari N, Mojdeh S, Marofi M. Comparison of methods to support the survival of peripheral vein catheter in selected hospitals in Isfahan in 2017. MJMS. 2017; 60(2): 493500. [Persian]

2.Suliman M, Saleh W, Al-shiekh H, Taan W, AlBashtawy M. The incidence of peripheral intravenous catheter phlebitis and risk factors among pediatric patients. JPN. 2020; 50: 89-93. 3.Bitencourt ES, Leal C, Boostel R, Mazza VA, Felix VC, Pedrolo E. Prevalence of phlebitis related to the use of peripheral intravenous devices in children. Cogitare Enferm. 2018; (23)1: e49361. 
4.Kalani Z, Pourmovahed Z, Vaezi AA, Vaziri SF. Assessing the risk factors of phlebitis incidence related to peripheral catheter: Av Analytical Study. JHOSP. 2015; 14(3): 93-99. [Persian]

5.Ray-Barruel G, Grad Cert BA, Polit DF, Murfield JE, Rickard CM. Infusion phlebitis assessment measures: a systematic review. J Eval Clin Pract. 2014; 20:191-202.

6.Bolcato M, Russo M, Donadello D, Rodriguez D, Aprile A. Disabling outcomes after peripheral vascular catheter insertion in a newborn patient: A case of Medical Liability. Am J Case Rep. 2017; 18: 1126-1129.

7.VaraeiSh, GhafourzadehToomatari B, Kamalinejad M, Yekaninejad MS, Kazemi FS, Khadem E. Effect of Arnebia Euchroma poultice on the prevention pf peripheral intravenous catheter-related phlebitis: A randomized clinical trial. Hayat. 2018; 24(1): 59-70. [Persian]

8.Kolahdoozipour J, Abdollahzadeh F, Zamanzadeh V, Vahedi A, Lotfi M, Heidarizadeh M. The comparison of the effect of chlorhexidine gluconate $2 \%$ and alcohol ethylic $70 \%$ in prevention of phlebitis. J Tabriz Univ Med Sci. 2008; 30(3): 55-60. [Persian]

9.Enes S, Opitz AR. Phlebitis associated with peripheral intravenous catheters in adults admitted to hospital in the Western Brazilian Amazon. Revista da Escola de Enfermagem da USP. 2016; 50(2): 263-271.

10.Poormohamadi M, Farsi Z, Rajai N. The effects of $2 \%$ chlorhexidine gluconate solution on prevention of phlebitis related to peripheral venous catheter in patients hospitalized in cardiac care units of a military hospital. Military Caring Sci. 2017; 4(1): 19-29. [Persian]

11.Bagheri-Nesami M, Khodadadian-Miri J, Yazdani-Cherati J, Tabiban S, Ala Sh. The comparison of $2 \%$ Nitroglycerin ointment and $2 \%$ Chlorhexidine solution effect in preventing catheter-related phlebitis. J Babol Univ Med Sci. 2014; 16(6):7-15. [Persian]

12. Amouei Foumani S, Paryad E, Ghanbari Khanghah A, Kazemnezhad Leili E. Complications of peripheral intravenous catheters during 72 hours after Insertion. J Holist Nurs Midwifery. 2019; 29(3): 137-144.

13.Mohseni M, Akbari H, Hekmat po. D, Anbari KH. Comparison of the effect of Clobetasol ointment and sterile gauze dressing on prevention of phlebitis caused by peripheral venous catheter in patients admitted to a surgery ward. MCS. 2018; 5(1): 72-79. [Persian]

14.Mosayebi N, Sharifpour SZ, Asgari F, Atrkarroushan Z, Pasdaran A. The efficacy and safety of Sesame oil in prevention of chemotherapy-induced phlebitis in children with acute lymphoblastic leukemia. Iran J Ped Hematol Oncol. 2017; 7(4): 198-206.

15.Eghbali-Babadi M, Ghadiriayan R, Hosseini SM. The effect of saline lock on phlebitis rates of patients in cardiac care units. Iran J Nurs Midwifery Res. 2015; 20(4): 496-501.

16.Kliegman RM, Stanton BF, St Geme JW, Schor NF, Behrman RE. Nelson Text book of pediatrics. 20 $0^{\text {th }}$ ed. New York: Elsevier, 2016: 617, 1023.

17.Ben Abdelaziz R, Hafsi H, Hajji H, Boudabous H, Ben Chehida A, Marbet A, et al. Peripheral venous catheter complications in children: predisposing factors in a multicenter prospective cohort study. BMC Pediatrics. 2017; 17: 208.

18.O'Grady NP, Alexander M, Burns LA, Dellinger EP, Garland J, Heard SO, et al. Summary of recommendations: guidelines for the prevention of intravascular catheter-related infections. Clin Infect Dis. 2011; 52: 1087e1099.

19.Xu L, Hu Y, Huang X, Fu J, Zhang J. Clinically indicated replacement versus routine replacement of peripheral venous catheters in adults: A nonblinded, cluster-randomized trial in China. Int J Nurs Pract. 2017; 23(6): e12595.

20.Abusafia BMR, Boztepe H. Evaluation of peripheral intravenous catheter-induced local complication in pediatrics. J Clin Nurs. 2017; doi: 10.1111/jocn. 13730.

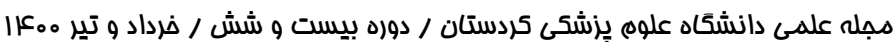


21.Awasthi Sh. Improving management of dehydration in children younger than 5 years in low-and-middle-income countries. Lancet Glob Health. 2016; 4(10): e674-e675.

22.Malyon L, Ullman AJ, Phillips N, Young J, Kleidon T, Murfield J, et al. Peripheral intravenous catheter duration and failure in paediatric acute care: A prospective cohort study. EMA. 2014; 26: 602-608.

23.Urbanetto JS, Peixoto CG, May TA. Incidence of phlebitis associated with the use of peripheral IV catheter and following catheter removal. RLAE. 2016; 24: e2746.

24.Menendez JJ, Verdu C, Calderon B, Gomez-Zamora A, Schuffelmann C, de la Cruz JJ, et al. Incidence and risk factors of superficial and deep vein thrombosis associated with peripherally inserted central catheters in children. J Thromb Haemost. 2016; 14: 2158-68.

25.Li XF, Liu W, Qin Y. Nurses̉ perception of risk factors for infusion phlebitis: A crosssectional survey. Chin Nurs Res. 2016; 3: 37-40.

26.Goudet V, Timsit JF, Lucet JC, Lepape A, Balayn D, Seguin S, et al. Comparison of four skin preparation strategies to prevent catheter-related infection in intensive care unit (CLEAN trial): a study protocol for a randomized controlled trial. Trials 2013; 14:114.

27.Marsh N, Webster J, Mihala G, Rickard CM. Devices and dressing to secure pheripheral venous catheters to prevent complications. Cochrane Database Syst Rev. 2015; 12(6): CD011070. doi:10.1002/14651858.CD011070.pub2.

28.Hugil K. Is there an optimal way of securing peripheral IV catheters in children? BJN. 2016; 25(19): S20-1.

29.Hwang D, Chiu N-Ch, Chang L, Peng Ch-Ch, Huang DT-N, Huang F-Y, et al. Vancomycin dosing and target attainment in children. JMII. 2017; 50(4): 494-9.

30.Drouet M, Chai F, Barthelemy Ch, Lebuffe G, Debaene B, Decaudin B, et al. Endothelial cell toxicity of vancomycin infusion combined with other antibiotics. AAC. $2015 ; 59(8)$ : 4901-6.

31.Caparas JV, Hu JP. Safe administration of vancomycin through a novel midline catheter: a randomized, prospective clinical trial. J Vasc Access. 2014; 15(4): 251-6.

32.Bruniera FR, Ferreira FM, Saviolli LR, Bacci MR, Feder D, da Luz Goncalves Pedreira $\mathrm{M}$, et al. The use of vancomycin with it's therapeutic and adverse effects: a review. Eur Rev Med Pharmacol Sci. 2015; 19(4):694-700.

33.Kumar M, Vandermeer B, Bassler D, Mansoor N. Low-dose heparin for prolonging the patency of peripheral intravenous catheters in adults- a systematic review and meta-analysis. Int J Med. 2014; 2(1): 13-21. 